\title{
Catalytic Transformation of Tall Oil into Biocomponent of Diesel Fuel
}

\author{
Jozef Mikulec, ${ }^{1}$ Andrea Kleinová, ${ }^{2}$ Ján Cvengroš, ${ }^{2}$ L'udmila Joríková, $^{1}$ and Marek Banič \\ ${ }^{1}$ VÚRUP a.s., Vlčie hrdlo, 82003 Bratislava, Slovakia \\ ${ }^{2}$ Faculty of Chemical and Food Technology, Slovak University of Technology, Radlinského 9, 81237 Bratislava, Slovakia
}

Correspondence should be addressed to Jozef Mikulec, jozef.mikulec@vurup.sk

Received 16 October 2011; Revised 17 December 2011; Accepted 31 December 2011

Academic Editor: David Kubička

Copyright ( $) 2012$ Jozef Mikulec et al. This is an open access article distributed under the Creative Commons Attribution License, which permits unrestricted use, distribution, and reproduction in any medium, provided the original work is properly cited.

\begin{abstract}
One of the conventional kraft pulp mills produce crude tall oil which is a mixture of free fatty acids, resin acids, sterols, terpenoid compounds, and many others. This study is devoted to the issue of direct transformation of crude tall oil in a mixture with straight-run atmospheric gas oil to liquid fuels using three different commercial hydrotreating catalysts. Diesel fuel production is an alternative to incineration of these materials. High catalytic activity was achieved for all tested catalysts in temperature range $360-380^{\circ} \mathrm{C}$, under 5.5 MPa hydrogen pressure and ratio $\mathrm{H}_{2}$ /feedstock 500-1000 $\mathrm{l} / \mathrm{l}$. Crude tall oil can be converted to diesel oil component via simultaneous refining with straight-run atmospheric gas oil on $\mathrm{NiMo} / \mathrm{Al}_{2} \mathrm{O}_{3}$ and NiW/ $\mathrm{Al}_{2} \mathrm{O}_{3}$-zeolite catalysts. All tested catalysts had very good hydrodenitrogenation activity and high liquid yield were at tested conditions.
\end{abstract}

\section{Introduction}

One of the modes of reducing the share of green house gases (GHG) emissions at energy production lies in the utilization of biomass and wastes. In the initial step, the known technological processes and feedstock commonly applied in foodstuff processing industry were utilized to produce first generation biocomponents. The use of fatty acid esters, bioalcohol, and ETBE is common at present. First-generation biocomponents are usually more expensive when compared to petroleum-based fuels. Competition with foodstuff production is questionable as well. The actual system based on indicative targets of reaching the total energy content or volume of biocomponents does not support priorities of biocomponents utilization with low-cost GHG emission decrease.

The regulatory mechanisms should be stipulated in a way that allow finds a possible reduction in the GHG emission for various biofuels and foodstuffs. Biofuels should be supported through an efficiency increase of current biocomponents and development of new improved procedures. The regulatory mechanism should not act as a barrier for new biofuel types.

One of the possible solutions is represented by the introduction of second generation biocomponents originated from wastes. Crude tall oil (CTO) [1] is a byproduct of paper production from coniferous wood by the Kraft pulping process. As an average, $20-30 \mathrm{~kg}$ tall oil $/$ ton wood is produced. It contains $30-50 \%$ wt. of free fatty (mainly oleic and linolic) acids, $40-60 \%$ of rosin acids (abietic and pimaric acids), and $10-15 \%$ of unsaponifiables containing $2-4 \%$ of sterols, fatty alcohols, phenols and hydrocarbons. Free fatty acids (FFAs) and rosin acids (RAs) can be separated by vacuum rectification. Tall pitch as a distillation residue is used as a source of phytosterols or simply for energy production purposes. The FFA fraction may be converted through esterification by methanol to fatty acids methyl esters (FAME) usable in engine fuels.

Crude tall oil can be directly used in the field of biofuels by the following procedure as well [2]. Performing FFA esterification with methanol, FFAs are converted to FAME which can be distilled off from the mixture, preferably using a film-type vacuum evaporator. Distillate $(48-52 \%$ yield relating to CTO input) complies with the standard EN 14214 except for one parameter-sulphur content reaching about $1200 \mathrm{mg} / \mathrm{kg}$, while according to the standard, not more than $10 \mathrm{mg} / \mathrm{kg}$ is acceptable.

Within our up-to-now performed study on CTO esterification with methanol $(\mathrm{MeOH})$ in a batch reactor and 
isolation of the formed tall oil fatty acid methyl esters (TOFAME), next significant facts have been observed.

CTO can undergo esterification without any pretreatment. Esterification carried out in a classic batch arrangement without formed water withdrawal proceeds relatively smoothly. The reaction time is $4-5$ hours, the optimum $\mathrm{MeOH}$ : FFA molar ratio is about 7. Preferably, FFAs undergo esterification while RAs are not subjected to esterification. In a GL chromatogram, the peaks corresponding to FAME are present, those of RAME (rosin acids methyl esters) are absent, that is, all present FFA were completely transformed to FAME. The course of reaction can be cosily monitored as a decrease of acid value (AV). The final AV corresponding to conversion of all present FFAs to their methyl esters can be calculated in advance. $\mathrm{H}_{2} \mathrm{SO}_{4}$ acts as an efficient catalyst of the reaction; its $0.5 \%$ addition relative to CTO is adequate. After esterification and elimination of the formed water and unreacted $\mathrm{MeOH}$, the reaction mixture can be rather efficiently separated by vacuum distillation in a film-type evaporator. TOFAME distillate is obtained in $48-52 \%$ yield relative to the CTO feed. The AV of the distilled TOFAME varies in the range of about 8 to $12 \mathrm{mg} \mathrm{KOH} / \mathrm{g}$ and results from free RA. Esterification performed by an unconventional process arrangement is described in detail in [3]. Into a bottom part of the catalyst-containing CTO charge with the temperature of $110-120^{\circ} \mathrm{C}$ the liquid $\mathrm{MeOH}$ is continuously delivered, it evaporates and penetrates through CTO layer reacting intensively with FFA, simultaneously stirring the reaction mixture and, at the same time, carrying away the formed water. Due to the high temperature, the high local excess of $\mathrm{MeOH}$ to FFA, and due to the efficient elimination of water, the rate of the reaction is high and the desired conversion is reached within a short time [2].

Another option lies in technological processes of catalytic hydrogenation. Coll et al. [4] investigated transformation of rosin acids in the fraction of crude tall oil using chosen commercial catalysts of Ni-Mo or Co-Mo types. Obtained yields of the liquid were high $(68-82 \%)$, in particular at temperatures over $350^{\circ} \mathrm{C}$ and higher hydrogen partial pressure. Myllyoja et al. [5] tested free fatty acids fraction from tall oil using NiMo catalyst at hydrogen pressure 5,0 MPa, LHSV $=1.5 \mathrm{~h}^{-1}$, reaction temperatures $340-360^{\circ} \mathrm{C}$, and a ratio of $900 \mathrm{NL} \mathrm{H}_{2} / \mathrm{L}$ feedstock. Under these conditions, the catalyst underwent fast deactivation and high-molecular substances and aromatic compounds were formed. Bromine index increased during the test. In a patent application [6] of Stigsson and Naydenov the decarboxylation/oxygen elimination from modified crude tall oil is described. Impurities were eliminated from crude tall oil; light and heavy components were distilled off and the mixture of the $170-400^{\circ} \mathrm{C}$ fraction with vegetable oil and/or mineral oil was subjected to catalytic decarboxylation at $320-240^{\circ} \mathrm{C}$ using a hydrorefining catalyst.

Catalytic deoxygenation of triacylglycerides and other oxygen-containing bio-oils is an alternative to biogas oil production [7]. There are few ways to eliminate oxygen from the feed: (i) deoxygenation over supported noble metal catalysts; (ii) hydrodeoxygenation over metal sulphide catalysts. Metal catalyzed deoxygenation in the absence of hydrogen is an effective method for the conversion of triacylglycerides to liquid hydrocarbons. The distribution of products is influenced by the degree of unsaturation of feed and by the nature of the catalyst [8-12]. Renewable gas oil component can be produced by catalytic hydrotreating of triacylglycerides (TAGs) over supported sulphide catalysts in presence of hydrogen. Two main routes were observed simultaneously-hydrodeoxygenation (HDO) an hydrodecarboxylation [12-15]. The advantage of this catalysts is possibility to process waste TAG to clean hydrocarbons component [16-18]. Many authors verified a possibility of simultaneous hydrodesulphurization of straight run atmospheric gas oil and hydrodeoxygenation of vegetable oils and animal fats using hydrorefining catalysts—coprocessing [19-21]. One of the disadvantage is deactivation of metal sulphide catalysts. Hydrocracking of vacuum gas oil with TAG is another way to produce clean biogas oil component $[22,23]$. The technology of coprocessing allows the decrease of both investment and operational costs of biocomponent production and use wide variety of feed particularly nonfood origin. Some catalyst producer offers catalyst for stand-alone process and/or coprocessing. Stand-alone processing of TAG was realized by Neste Oil.

In this contribution, possibilities to process the mixtures of unseparated crude tall oil with straight-run atmospheric gas oil atmospheric gas oil using hydrocracking Ni-W catalyst and Ni-Mo hydrotreating catalysts were examined.

\section{Experimental Part}

The tests were performed in a tubular downflow isothermal fixed-bed reactor (the total volume $250 \mathrm{~mL}$ ) with catalytic bed of $100 \mathrm{~mL}$, feed range $100-1000 \mathrm{~mL} / \mathrm{h}$, operation temperature $360-380^{\circ} \mathrm{C}$, and operation pressure $5,5 \mathrm{MPa}$. Feed stock container and product lines were heated to prevent feed and product solidification. Catalyst was diluted with glass pellet to avoid channelling and minimize backmixing. The dimensions of the reactor were $500 \mathrm{~mm}$ (length) and $25 \mathrm{~mm}$ (inner diameter). The reactor had three electrically heated and controlled sections.

Reaction feed stock was fed into the reactor by a highpressure piston pump and mixed with hydrogen (Messer, $99,9 \%$ ) on the head of the reactor. Formed mixture, depending on the amount of the catalyst, passes through a bed of a catalyst. The temperature was measured by means of thermocouples and controlled by a PID regulators. The pressure was controlled by a backpressure regulator. The formed product passes subsequently through a cooler to a separator, where reaction gas is separated from the product. The liquid products were withdrawn after stabilization of reaction conditions $(6 \mathrm{~h})$ in two two-hour intervals and analyzed by offline gas chromatography after separation of the water phase. Reaction gas, after being discharged from the separator, passes through a gas flow meter allowing both to regulate and measure its amount. $\mathrm{H}_{2} \mathrm{~S}$ and $\mathrm{NH}_{3}$ were stripped by counter current nitrogen flow.

During the test, a representative sample of the gas was withdrawn and complex material balance was elaborated. In the liquid sample, a portion of aqueous and organic 
TABLE 1: Physical properties of straight-run atmospheric gas oil and crude tall oil.

\begin{tabular}{lccc}
\hline Parameter & Unit & AGO & CTO \\
\hline Density at $20^{\circ} \mathrm{C}$ & $\mathrm{kg} / \mathrm{m}^{3}$ & 843 & 952 \\
Sulphur content & $\mathrm{mg} / \mathrm{kg}$ & 9535 & 1610 \\
Nitrogen content & $\mathrm{mg} / \mathrm{kg}$ & 168.4 & $\mathrm{n} . \mathrm{a}$. \\
Bromine value & $\mathrm{g} \mathrm{Br} / 100 \mathrm{~g}$ & n.a. & 81.1 \\
Iodine value & $\mathrm{g} \mathrm{I}_{2} / 100 \mathrm{~g}$ & n.a. & 113 \\
Acid value & $\mathrm{mg} \mathrm{KOH} / \mathrm{g}$ & 0.02 & 138 \\
Sodium content & $\mathrm{mg} / \mathrm{kg}$ & n.a. & 27.7 \\
Potassium content & $\mathrm{mg} / \mathrm{kg}$ & n.a. & 6.5 \\
Calcium content & $\mathrm{mg} / \mathrm{kg}$ & n.a. & 1.1 \\
Magnesium content & $\mathrm{mg} / \mathrm{kg}$ & n.a. & 0.1 \\
Phosphorus content & $\mathrm{mg} / \mathrm{kg}$ & n.a. & 22.7 \\
\hline
\end{tabular}

AGO: straight-run atmospheric gas oil, CTO: crude tall oil.

phases was determined. In some experiments the feedstock was diluted with isooctane facilitating thus to follow the mechanism of transformation of tall oil components.

2.1. Feedstock. Crude depitched tall oil (Smurfit Kappa, Piteå, Sweden) was used in the tests. Straight-run atmospheric gas oil (atmospheric gas oil AGO) from the production unit AVD 6 of the refinery Slovnaft Bratislava, Slovak Republic was used within testing the simultaneous desulphurization of gas oil and crude tall oil. Some physical properties of straight-run atmospheric gas oil and crude tall oil are in Table 1. The portions of FFA present in TO are summarized in Table 2. Resin acids and unsaponifiable compounds were not analyzed in detail. According to CTO supplier the content of FFA was $45 \%$, of RA $30 \%$, and of the unsaponifiables $25 \%$.

2.2. Catalysts. Three commercial hydrocracking catalysts were used by the tests: $\mathrm{NiW} / \gamma-\mathrm{Al}_{2} \mathrm{O}_{3}+$ zeolit catalyst in sulphidized form, Ni-Mo hydrotreating catalyst, and Ni-W hydrotreating catalyst. Their approximate composition is in Table 3. Sulphidization occurred directly in a pressure vessel in hydrogen atmosphere at the pressure of $3 \mathrm{MPa}$ using 5\% solution of dimethyldisulphide in gas oil. The catalyst was dried at $120^{\circ} \mathrm{C}$ in a stream of nitrogen. The temperature gradually increased with the gradient $100^{\circ} \mathrm{C} / \mathrm{h}$ up to $350^{\circ} \mathrm{C}$, kept isothermal at $250^{\circ} \mathrm{C}$ for $1 \mathrm{~h}$ and at $350^{\circ} \mathrm{C}$ for $4 \mathrm{~h}$.

2.3. Analytics. Reaction gas was withdrawn into glass sample flasks and analyzed by gas chromatography following the standard UOP 539-87 on an instrument Shimadzu GC 17 A. The chromatograph was equipped with an injection loop, flame-ionization, and thermal conductivity detectors, software for pressure and temperature control and data collection in the PC. After reaching steady-state operational conditions and performing sufficient flushing of the injection loop with the sample, the analysed sample was injected into the instrument using a $10 \mu \mathrm{L}$ injection loop. Temperature and pressure program/mode was put into operation. In a three columns and two switch valves system, oxygen, nitrogen, carbon dioxide, carbon oxide, hydrogen, and light hydrocarbons (from methane to n-pentane) were separated. Hydrocarbons higher than n-pentane were eluated in one peak. Individual components were identified based on the elution times of the components present in a standard mixture and determined comparing responses of the components present in the standard mixture and in the sample. Column types: molecular sieve, precolumn: $5 \mathrm{~m} \times 0.53 \mathrm{~mm} \times 3 \mu \mathrm{m}$ SE 54, and analytical column: $60 \mathrm{~m} \times$ $0.53 \mathrm{~mm}$ CP-SilicaPLOT.

Boiling point-based distribution (simulated distillation) was determined according to ASTM D 2887 with a Network GC System $6890 \mathrm{~N}$ (Agilent Technologies) equipped with an autosampler, on-column injector, FID detector, and separation column: RMX1 $15 \mathrm{~m} \times 0.53 \mathrm{~mm} \times 2.65 \mu \mathrm{m}$.

The content of fatty acids in tall oil (TOFAME) was determined following ISO 5509 and EN 14103. Tall oil sample was saponified under a reflux condenser with methanolic solution of sodium hydroxide; the formed soaps were converted to fatty acids methyl esters by the reaction with a methanolic solution of boron trifluoride. Subsequent to addition of internal standard in isooctane, the formed fatty acids esters were extracted to isooctane layer by agitation. The content and abundance of individual TOFAME were determined using GC analysis of the dried isooctane layer. A gas chromatograph HEWLET PACKARD G 1800A GCD System with a FID detector and split injector was used for the analysis. A capillary column ZB-WAX $(30 \mathrm{~m} \times 0.32 \mathrm{~mm}$, df $0.5 \mu \mathrm{m}$ ) was used for the separation. The content of TOFAME was obtained by the internal standard method.

The content of aromatic hydrocarbons in the final product and the used AGO was determined according to EN 12916 by HPLC method with RID detection on an instrument HPLC System, Agilent Technologies, 1200 Series. As a mobile phase, n-heptane was used; aromatic hydrocarbons were separated in groups by a number of aromatic rings using a medium polar column ZORBAX $\mathrm{NH}_{2} 5$ analytical column $(4.6 \times 250) \mathrm{mm}$. The content of individual aromatic groups was determined by the external standard method using o-xylene, fluorene, and phenathrene as reference compounds.

The sulphur content was determined by ultraviolet fluorescence technique according to STN EN ISO 20846 with an instrument ANTEK 9000S Pyro-Fluorescent Sulfur.

Nitrogen content was determined on an instrument TN/TSuv3000. The used operation procedure is described in ASTM D 4629 Standard Test Method.

Cetane number was evaluated using a portable diesel fuel analyser providing fast analysis of fuel composition. The Turbine/Diesel Fuel Analyzer (PetroSpec) uses the technique of infrared spectroscopic analysis for resolution and determination of individual components in the fuel sample. After obtaining the infrared absorption spectra, the instrument converts the spectral data to the parameter values.

Density of the modified samples was determined between individual steps of the experiment by oscilometric method according to the standard STN EN ISO 12185 with a commercially available instrument DMA 4500 M (Anton Paar) equipped with an oscillating U-tube. 
TABLE 2: Crude tall oil—content of free fatty acids.

\begin{tabular}{lcccccccc}
\hline Acid & C14:0 & C14:1 & C16:0 & C16:1 & C18:0 & C18:1 & C18:2 & C18:2 conj. \\
\hline \% wt. & 0.07 & 0.04 & 1.99 & 0.13 & 0.83 & 11.53 & 24.52 & 5.47 \\
\hline Acid & $\mathrm{C} 18: 3$ & $\mathrm{C} 20: 0$ & $\mathrm{C} 20: 1$ & $\mathrm{C} 22: 0$ & $\mathrm{C} 22: 1$ & $\mathrm{C} 24: 0$ & $\mathrm{C} 24: 1$ & total \\
\% wt. & 0.90 & 0.54 & 0.49 & 0.70 & 0.10 & 0.05 & 0.01 & 47.36 \\
\hline
\end{tabular}

TABLE 3: Approximate composition of catalysts.

\begin{tabular}{lccc}
\hline Component & $\begin{array}{c}\text { Catalyst A } \\
\text { content, \% wt. }\end{array}$ & $\begin{array}{c}\text { Catalyst B } \\
\text { content, \% wt. }\end{array}$ & $\begin{array}{c}\text { Catalyst C } \\
\text { content, \% wt. }\end{array}$ \\
\hline $\mathrm{NiO}$ & $5-10$ & 3.0 & $1-5$ \\
$\mathrm{MoO} 3$ & $20-24$ & - & - \\
$\mathrm{WO}_{3}$ & - & 19 & $10-15$ \\
$\mathrm{Al}_{2} \mathrm{O}_{3}$ & $40-50$ & Balance 78 & $84-70$ \\
$\mathrm{SiO}_{2}$ & $25-30^{*}$ & - & - \\
$\begin{array}{l}\text { Aluminum } \\
\text { phosphate }\end{array}$ & - & - & $5-10$ \\
\hline
\end{tabular}

${ }^{*} \mathrm{SiO}_{2}$ is in form of aluminosilicate.

Acid values were determined by potentiometry according to the method described in standards STN 656214 or ASTM D 664. When determining the acid number, a commercially available instrument, automatic titrator 716 DMS TITRINO (Metrohm), was used.

At assessing or evaluating the samples obtained after individual steps of the whole experiment in the fuel testing laboratory, IR spectroscopy was used, too. To scan IR spectra in the region from $4000 \mathrm{~cm}^{-1}$ to $400 \mathrm{~cm}^{-1}$, Fourier transform infrared spectrometer AVATAR 330 (Thermo Nicolet) and optical $\mathrm{KBr}$ cell of $0.040 \mathrm{~mm}$ were used.

To determine the share of RA and FA in CTO it is possible to benefit from ${ }^{13} \mathrm{C}$ NMR spectroscopy [1] exploiting a different chemical shift of the carboxylic carbon atom in RA and FA. The RA carboxyl is bonded to quarternary carbon while that of FA to secondary carbon. Chemical shifts of RA and FA carboxyls are in ${ }^{13} \mathrm{C}$ NMR spectra in the regions of 184-186 ppm and 180-181 ppm, respectively. The share of RA and FA can be easily determined based on the integrated intensities of the corresponding peaks. ${ }^{13} \mathrm{C}$ NMR spectral studies were measured with the apparatus VARIAN VXR 600 in the presence of deuterated chloroform as a solvent.

\section{Results and Discussion}

3.1. Hydrotreating of CTO in Solvent. Crude tall oil is dark brown viscous liquid of characteristic odour. CTO was dissolved in isooctane ( 5 and $20 \%$ vol.) and was kept by heating at $50^{\circ} \mathrm{C}$ preventing thus the formation and deposition of solid rosin acids. CTO was in isooctane fully soluble.

Catalyst A was used to test $5 \%$ vol. solution of CTO in isooctane in the temperature range $320-380^{\circ} \mathrm{C}$, hydrogen partial pressure of $5.5 \mathrm{MPa}, \mathrm{LHSV}=1 \mathrm{~h}^{-1}$, and the ratio of hydrogen to the tall oil $1000 \mathrm{l} / \mathrm{l}$ and $500 \mathrm{l} / \mathrm{l}$. With increasing temperature, the increased concentration of $\mathrm{CO}$ and $\mathrm{CO}_{2}$ as a result of decarboxylation reactions of acids present is registered. In the same ratio, the concentration of isobutane

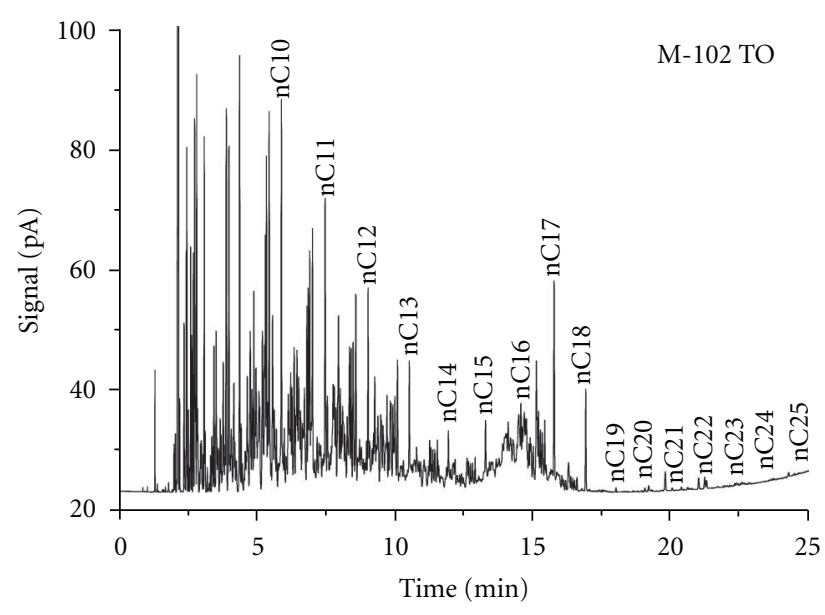

FIGURE 1: GC chromatogram of liquid product-hydrotreating CTO in isooctane on catalyst A.

in the gas was increased. The reaction was carried out mainly at $380^{\circ} \mathrm{C}$. The change of the hydrogen/tall oil ratio from the value of 1000 to $500 \mathrm{l} / \mathrm{l}$ had not a significant impact on the reactions.

The formation of $\mathrm{CO}$ can be explained by secondary reactions of $\mathrm{CO}_{2}$ and high excess hydrogen in the presence of a catalytic system. In the gaseous reaction products, methane, propane and water as a result hydrodeoxygenation free fatty acids were observed, respectively. The progress of reaction was checked with a higher concentration of CTO in isooctane (20\% vol.).

At a reaction temperature of $380^{\circ} \mathrm{C}$, hydrogen partial pressure of $5.5 \mathrm{MPa}$, LHSV $=1 \mathrm{~h}^{-1}$ and the ratio of hydrogen to the CTO 10961/1, the light brown solution with characteristic odour changed to a clear solution, which had a strong diesel smell. Reaction water content was $0.8 \mathrm{wt} \%$. The gas share was $3.1 \mathrm{wt} \%$. and they had the highest content of isobutane, $\mathrm{CO}, \mathrm{CO}_{2}$, and propane. $\mathrm{GC}$ analysis indicates that on the catalyst A takes place the hydrodeoxygenation and hydrodecarboxylation of fatty acids to n-alkanes. The chemical structure of CTO resin acids is similar to that of abietic or dehydroabietic acids [4]. The resin acids were hydrogenated to the cyclanes hydrocarbons and water. Second mechanism was hydrodecarboxylation to cyclic hydrocarbons and $\mathrm{CO}_{2}$

$$
\begin{gathered}
\mathrm{R}-\mathrm{COOH}+\mathrm{H}_{2} \longrightarrow \mathrm{R}-\mathrm{CH}_{3}+\mathrm{H}_{2} \mathrm{O} \\
\mathrm{R}-\mathrm{COOH} \longrightarrow \mathrm{R}-\mathrm{H}+\mathrm{CO}_{2} .
\end{gathered}
$$

Figure 1 shows GC chromatogram of product from hydrotreatment mixtures CTO in isooctane on catalyst A. As a side reaction cracking reaction to lighter hydrocarbons and isomerization takes place also on acidic centre of 


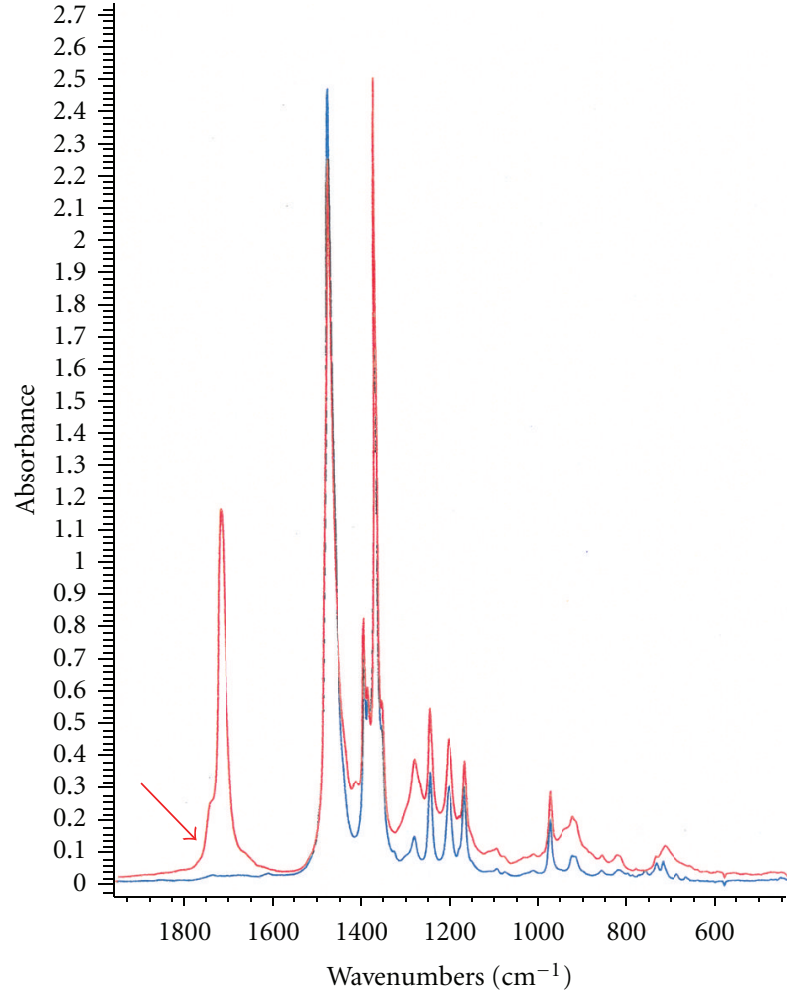

FIGURE 2: IR spectrum of $20 \%$ solution of CTO before (red line) and after reaction (blue line).

the catalyst (presence of the zeolite). The isomerization reaction was indicated by very low cloud point $\left(-20^{\circ} \mathrm{C}\right)$.

In Figure 2, IR spectrum of $20 \%$ solution of tall oil and reaction product is displayed indicating a total elimination of $\mathrm{C}=\mathrm{O}$ group at about $1680-1720 \mathrm{~cm}^{-1}$.

The degree of oxygen elimination was confirmed also by ${ }^{13} \mathrm{C}$ NMR spectra (Figure 3 ). Figure 2 shows a selected spectral part of CTO used for hydrogenation in isooctane. The lower spectra correspond to the introduced feedstock while the upper ones document the situation after hydrogenation. Comparison of the spectra leads to a conclusion that the peaks of functional groups of both acid types (FA + RA) fully disappeared.

To verify a possible mechanism of the conversion of resin acids to hydrocarbons, test was made with a solution of rosin in a mixture of isooctane and acetone. The largest part of the gas was isobutane, which suggests a predominant hydrocracking reaction of alkyl groups associated with the saturation of double bonds and ring opening of cycloaliphatic rings. In the liquid products cycloalkanes were dominant with carbon numbers of $\mathrm{C}_{5}$ through $\mathrm{C}_{12}$. Moreover, in liquid product were present saturated $n$ - and iso-alkanes but not olefinic compounds. Oxygen compounds were not detected.

Analysis of the total sulphur content manifested that the elimination of sulphur compounds from CTO by means of hydrogenation represents a more serious issue. In the feedstock was $322 \mathrm{mg} / \mathrm{kg}$ of total sulphur while in the product after reaction was $122 \mathrm{mg} / \mathrm{kg}$. The results indicate a content of refractory sulphur compounds.

3.2. Hydrotreating of Mixture CTO with AGO. The tests of hydrorefining and hydrodeoxygenation of the mixture of AGO with CTO were performed at 360 and $380^{\circ} \mathrm{C}$, hydrogen pressure $5.5 \mathrm{MPa}$, and two value of ration hydrogen to the feedstock ratios with three different hydrotreating catalysts A, B, and C. For testing, concentrations of CTO 20 vol. were used and $30 \%$ vol. were used also for catalyst A. CTO was fully soluble in AGO. The main target of the experiments was to compare the performance of the three different hydrotreating catalysts with respect to some selected performance criteria as liquid yield, cetane number, HDS, $\mathrm{HDO}$ and HDN activity, aromatics content, and density. The test results are listed in Tables 4,5 , and 6 .

3.3. Boiling Point Distribution. The method of simulated distillation was used for comparison of the catalysts performance. Shows Figure 4 the comparison of simulated distillation curve for catalysts $\mathrm{A}, \mathrm{B}$, and $\mathrm{C}$ with feed containing $20 \%$ vol. CTO in straight-run $\mathrm{AGO}$ at $380^{\circ} \mathrm{C}$, partial pressure hydrogen 5,5 $\mathrm{MPa}, \mathrm{LHSV}=1 \mathrm{~h}^{-1}$, and ratio hydrogen to feed about $1000 \mathrm{NL} / \mathrm{L}$. The distillation curves for the studied catalysts were inherently different. Catalyst A is suitable for hydrocracking of vacuum distillates and even at relatively low temperature and pressure the reaction of cracking took place. It is obvious from Figure 4 that the used hydrocracking catalyst A influences the formation of lighter components and lowers the end of distillation. The product from a catalyst A contains $17 \%$ vol. gasoline fraction to $150^{\circ} \mathrm{C}$. The initial boiling point and end of distillation were, however, lowered which indicate the substantial contribution of hydrocracking reactions. Products from the catalysts $B$ and $C$ were in the distillation range of gas oil. It is evident that the acidity of the catalyst determines the cracking reaction byproducts and must be balanced. The best catalyst from boiling point distribution point of view was the catalyst B.

3.4. HDS Activity of the Catalysts. Investigated mixture CTO in AGO contains different types of sulphur compounds. HDS activity was decreased from catalyst C $(99.26 \%)$ to B $(98,38)$ and $A(96,99)$. In neither of the experiments, desulphurization down to $10 \mathrm{mg} / \mathrm{kg}$ was not reached which documents the presence of resistant sulphur compounds and necessity to exploit a combination of the higher active catalysts.

3.5. HDN Activity. Nitrogen content was reduced below $2 \mathrm{mg} / \mathrm{kg}$. All tested catalyst had very good HDN activity but different one. The best HDN activity had catalyst $\mathrm{C}$ $(97,49 \%)$, catalyst A has $95.67 \% \mathrm{HDN}$ efficiency and HDN efficiency, of catalyst B was $89,62 \%$.

3.6. HDO Activity. The oxygen removal was very high $(99,9 \%)$, highest HDO activity had catalyst C.

3.7. HDA Activity. The influence of tungsten on hydrogenation of aromatic compounds and aromatic rings opening 


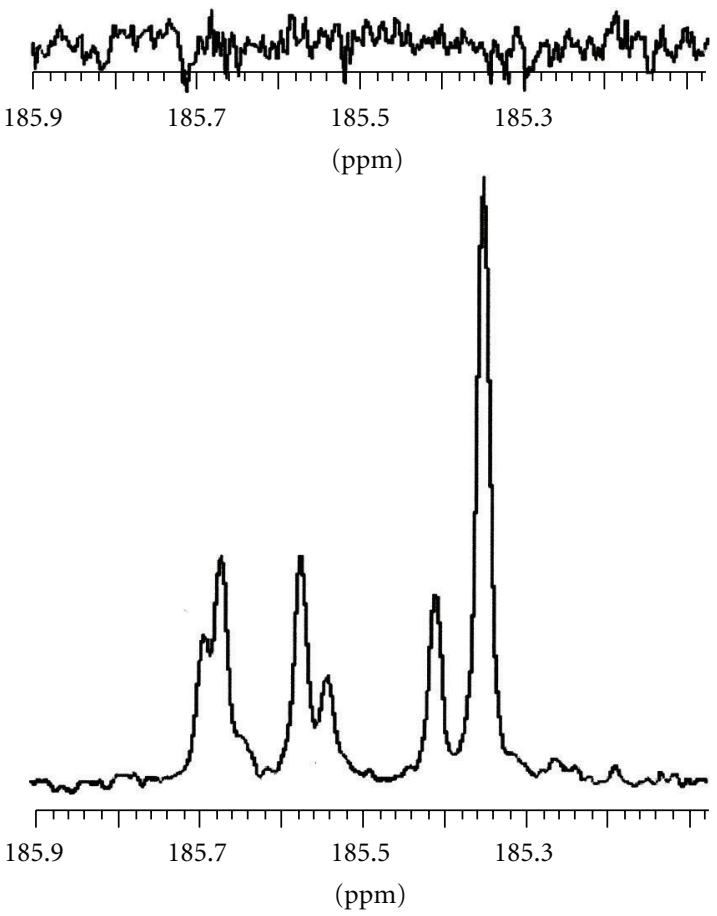

(a)

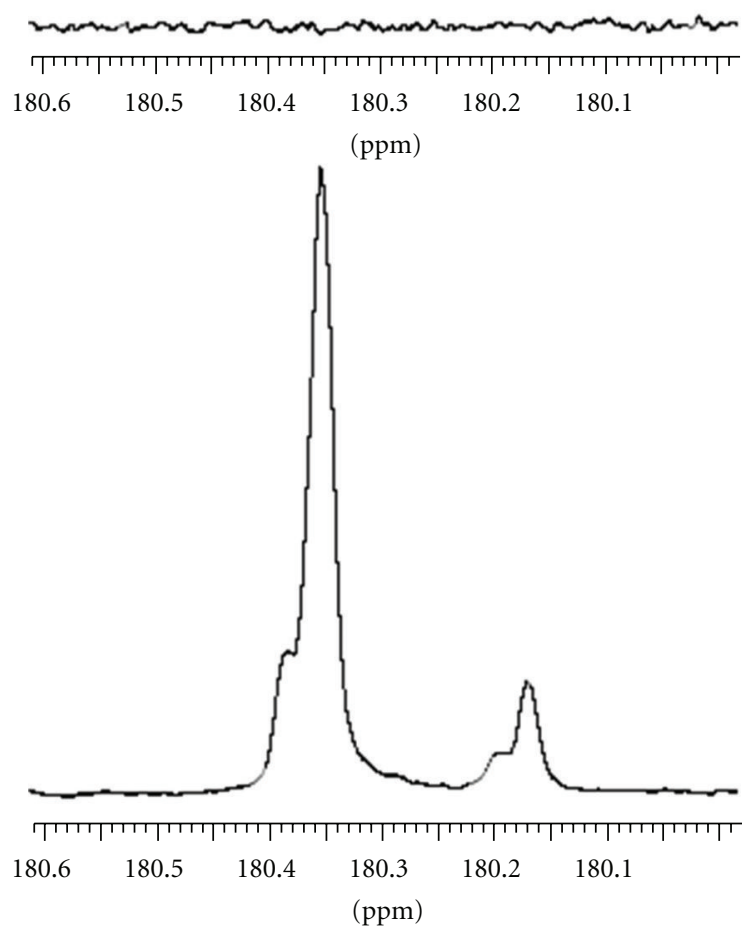

(b)

Figure 3: ${ }^{13} \mathrm{C}$ NMR spectrum of CTO after and before hydrogenation. The left spectra belong to RA (184-186 ppm). The right spectra to FFA (180-181 ppm).

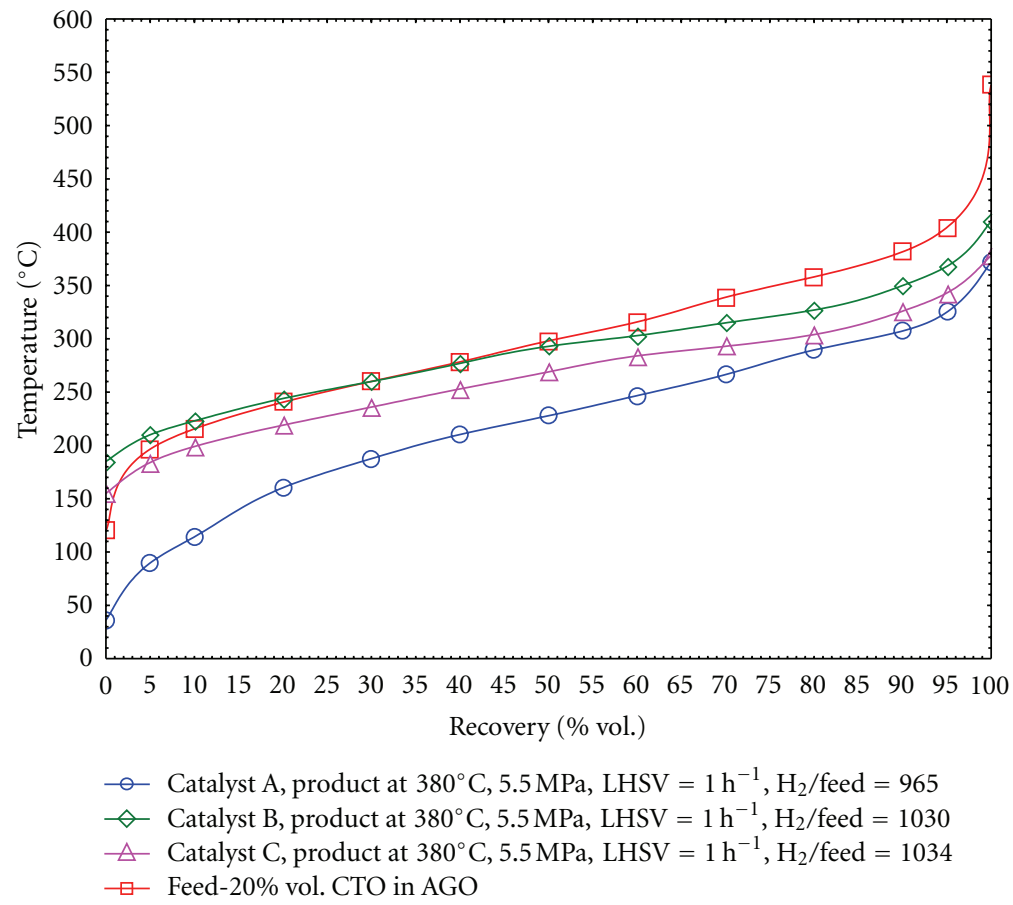

FIGURE 4: Simulated distillation curves of the feedstock and selected products of hydrorefining. 
TABLE 4: Results of hydrorefining of the mixtures of gas oil and crude tall oil; catalyst A.

\begin{tabular}{|c|c|c|c|c|c|c|}
\hline \multirow{2}{*}{$\frac{\text { Parameter }}{\text { Temperature, }{ }^{\circ} \mathrm{C}}$} & \multicolumn{6}{|c|}{ Products } \\
\hline & \multicolumn{2}{|c|}{380} & \multicolumn{2}{|c|}{360} & \multicolumn{2}{|c|}{380} \\
\hline Pressure, $\mathrm{MPa}$ & \multicolumn{6}{|c|}{5.5} \\
\hline LHSV, $\mathrm{h}^{-1}$ & \multicolumn{6}{|c|}{1} \\
\hline $\mathrm{H}_{2} /$ feed, $\mathrm{L} / \mathrm{L} \cdot \mathrm{h}$ & 965 & 504 & 970 & 525 & 985 & 544 \\
\hline CTO content in feed, \% vol. & \multicolumn{4}{|c|}{20} & \multicolumn{2}{|c|}{30} \\
\hline Hydrocarbons $\mathrm{C}_{1}-\mathrm{C}_{5}, \%$ wt. & 1,42 & 0,93 & 0,57 & 1,19 & 1,19 & 0,45 \\
\hline Propane, \% wt. & 0,60 & 0,40 & 0,24 & 0,51 & 0,51 & 0,32 \\
\hline CO content, \% wt. & 0,84 & 0,55 & 0,34 & 0,71 & 0,70 & 1,27 \\
\hline $\mathrm{CO}_{2}$ content, $\%$ wt. & 0,28 & 0,18 & 0,11 & 0,23 & 0,23 & 0,96 \\
\hline Liquid product, \% wt. & 96.00 & 97.21 & 98.05 & 97.36 & 96.64 & 95.85 \\
\hline Reaction water, \% wt. & 0.86 & 0.73 & 0.69 & 1.07 & 0.73 & 1.15 \\
\hline Sulphur content, $\mathrm{mg} / \mathrm{kg}$ & 239 & 120 & 176 & 291 & 84 & 97 \\
\hline Acid value, mg KOH/g & 0.01 & 0.01 & 0.04 & 0.02 & 0.02 & 0.04 \\
\hline Nitrogen content, $\mathrm{mg} / \mathrm{kg}$ & 1 & 1.2 & 1.5 & 1.6 & 0.8 & 0.9 \\
\hline Density at $15^{\circ} \mathrm{C} . \mathrm{kg} / \mathrm{m}^{3}$ & 801 & 813 & 814 & 814 & 826 & 830 \\
\hline Monoaromatics, \% wt. & 16.5 & 19.6 & 20 & 21.2 & 19.8 & 20.4 \\
\hline$\Sigma$ Di- and Tri-aromatics, \% wt. & 1.66 & 3.32 & 2.68 & 2.39 & 3.23 & 3.99 \\
\hline Cetane number & 56,5 & 55 & 53,5 & 54 & 57 & 56,8 \\
\hline
\end{tabular}

TABLE 5: Results of hydrorefining of the mixtures of gas oil and crude tall oil; catalyst B.

\begin{tabular}{|c|c|c|c|c|}
\hline \multirow{2}{*}{$\begin{array}{l}\text { Parameter } \\
\text { Temperature, }{ }^{\circ} \mathrm{C}\end{array}$} & \multicolumn{4}{|c|}{ Products } \\
\hline & \multicolumn{2}{|c|}{380} & \multicolumn{2}{|c|}{360} \\
\hline Pressure, $\mathrm{MPa}$ & \multicolumn{2}{|c|}{5.5} & \multicolumn{2}{|c|}{5,5} \\
\hline LHSV, $\mathrm{h}^{-1}$ & \multicolumn{2}{|c|}{1} & \multicolumn{2}{|c|}{1} \\
\hline $\mathrm{H}_{2} /$ feed, $\mathrm{L} / \mathrm{L} \cdot \mathrm{h}$ & 1030 & 541 & 1034 & 531 \\
\hline CTO content in feed, \% vol. & \multicolumn{4}{|c|}{20} \\
\hline Hydrocarbons $\mathrm{C}_{1}-\mathrm{C}_{5}$, \% wt. & 0,98 & 0,48 & 0,55 & 0,37 \\
\hline Propane, \% wt. & 0,38 & 0,33 & 0,69 & 0,46 \\
\hline CO content, \% wt. & 0,65 & 0,32 & 0,68 & 0,48 \\
\hline $\mathrm{CO}_{2}$ content, $\%$ wt. & 0,38 & 1,25 & 2,07 & 1,40 \\
\hline Liquid product, \% wt. & 96.74 & 97.73 & 96.00 & 95.67 \\
\hline Reaction water, \% wt. & 0.86 & 1.02 & 1.93 & 2.93 \\
\hline Sulphur content, mg/kg & 128.8 & 308.3 & 114.2 & 38.2 \\
\hline Acid value, mg KOH/g & 0.15 & 0.03 & 0.11 & 0.04 \\
\hline Nitrogen content, mg/kg & 2.4 & 2.8 & 1.5 & 1.8 \\
\hline Density at $15^{\circ} \mathrm{C} . \mathrm{kg} / \mathrm{m}^{3}$ & 839 & 835 & 832 & 833 \\
\hline Monoaromatics, \% wt. & 25 & 23.2 & 20.7 & 21.4 \\
\hline$\Sigma$ Di- and Tri-aromatics, \% wt. & 2.9 & 2.6 & 2 & 2 \\
\hline Cetane number & 55 & 56.4 & 55.8 & 56.7 \\
\hline
\end{tabular}

was significant. The content of compounds containing three and two aromatic rings decreased, while that with one ring increased. HDA activity of the catalysts $\mathrm{B}$ and $\mathrm{C}$ was not significant.

3.8. Catalyst Activity. Within a short-term test lasting $72 \mathrm{~h}$ no deactivation of the catalyst expressed by means of the acid value of the product was observed in spite of the fact that no precatalyst intended to eliminate catalytic poisons from tall oil was used.
3.9. Cetane Number. Cetane number is very important value for evaluation of combustion of motor fuel used in compression-ignition engines. Cetane number of the products was high in all catalyst tests. This result only confirms changes in composition of products due to the rising of $n$-alkanes concentration.

3.10. Density. The value of the density is an important parameter for the assessment of the possibilities of mixing of the fuel. Products of the joint coprocessing AGO and 
TABLE 6: Results of hydrorefining of the mixtures of gas oil and crude tall oil; catalyst C.

\begin{tabular}{|c|c|c|c|c|}
\hline \multirow{2}{*}{$\begin{array}{l}\text { Parameter } \\
\text { Temperature, }{ }^{\circ} \mathrm{C}\end{array}$} & \multicolumn{4}{|c|}{ Products } \\
\hline & \multicolumn{2}{|c|}{380} & \multicolumn{2}{|c|}{360} \\
\hline Pressure, $\mathrm{MPa}$ & \multicolumn{2}{|c|}{5.5} & \multicolumn{2}{|c|}{5,5} \\
\hline LHSV, $\mathrm{h}^{-1}$ & \multicolumn{2}{|c|}{1} & \multicolumn{2}{|c|}{1} \\
\hline $\mathrm{H}_{2} /$ feed, $\mathrm{L} / \mathrm{L} \cdot \mathrm{h}$ & 1034 & 511 & 1054 & 503 \\
\hline CTO content in feed, $\%$ vol. & \multicolumn{4}{|c|}{20} \\
\hline Hydrocarbons $\mathrm{C}_{1}-\mathrm{C}_{5}, \%$ wt. & 1,27 & 1,14 & 0,68 & 0,44 \\
\hline Propane, \% wt. & 0,49 & 0,44 & 0,53 & 0,27 \\
\hline CO content, \% wt. & 0,28 & 0,99 & 0,22 & 0,60 \\
\hline $\mathrm{CO}_{2}$ content, $\%$ wt. & 2,57 & 2,93 & 1,66 & 0,67 \\
\hline Liquid product, \% wt. & 95,12 & 94,52 & 95,72 & 96,64 \\
\hline Reaction water, \% wt. & 2,31 & 2,55 & 2,62 & 1,38 \\
\hline Sulphur content, $\mathrm{mg} / \mathrm{kg}$ & 58.8 & 100.5 & 218.4 & 473.4 \\
\hline Acid value, mg KOH/g & 0.14 & 0.17 & 0.05 & 0.07 \\
\hline Nitrogen content, $\mathrm{mg} / \mathrm{kg}$ & 0.58 & 0.8 & 1 & 1.2 \\
\hline Density at $15^{\circ} \mathrm{C} . \mathrm{kg} / \mathrm{m}^{3}$ & 831 & 837 & 830 & 829 \\
\hline Monoaromatics, \% wt. & 21.2 & 24.5 & 16.8 & 16.8 \\
\hline$\Sigma$ Di- and Tri-aromatics, $\%$ wt. & 2.3 & 2.9 & 1.4 & 1.5 \\
\hline Cetane number & 56.6 & 56.3 & 59 & 59 \\
\hline
\end{tabular}

CTO comply with the standard for diesel fuel in the case of catalysts $\mathrm{B}$ and $\mathrm{C}$. The straight chain alkanes can undergo isomerization and partly cracking to produce isomerised alkanes with lighter alkanes in case of catalyst A. In this case light fraction must be eliminated by stripping before use in diesel fuel.

\section{Conclusions}

NiW and NiMo hydrocracking/hydrotreating catalysts were found to be active for hydrotreating of crude depitched tall oil and in coprocessing with atmospheric gas oil. The reaction pathway of crude tall oil involves hydrogenation of double bonds, decarboxylation, hydrodeoxygenation, isomerization, and hydrocracking of alkane and cyclic structures. Crude tall oil can be converted to a component of diesel fuel via simultaneous refining of atmospheric gas oil and tall oil using the commercial hydrotreating catalysts at $360-380^{\circ} \mathrm{C}$ and hydrogen pressure of 5.5 MPa. Small amounts of remaining impurities in feedstock (metals) must be eliminated through guard bed catalyst. The difference between the catalysts was in HDS activity of refractory sulphur species. The selectivity for the maximum diesel range hydrocarbons must be controlled by appropriate acidity of catalyst support.

\section{Acknowledgment}

This work was supported by Slovak Research and Development Agency, Project no. APVV 10-0665-2010

\section{References}

[1] J. Cvengroš, Ľ Malík, M. Košík, and I. Šurina, "Fractionation of tall oil," Chemicky Prumysl, vol. 35, pp. 542-545, 1985 (Slovak).
[2] R. Mikulášik, I. Šurina, S. Katuščák, J. Cvengroš, and M. Polovka, "Preparation of biodiesel from tall oil," Chemical Papers, vol. 99, pp. 1234-2345, 2008.

[3] T. Kocsisová, J. Cvengroš, and J. Lutišan, "High-temperature esterification of fatty acids with methanol at ambient pressure," European Journal of Lipid Science and Technology, vol. 107, no. 2, pp. 87-92, 2005.

[4] R. Coll, S. Udas, and W. A. Jacoby, "Conversion of the rosin acid fraction of crude tall oil into fuels and chemicals," Energy and Fuels, vol. 15, no. 5, pp. 1166-1172, 2001.

[5] J. Myllyoja, J. Aalto, and E. Harlin, "Process for the manufacture of diesel range hydrocarbons," WO 2007003708 (A1), 2007.

[6] L. Stigsson and V. Naydenov, "Conversion of crude tall oil to renewable feedstock for diesel range fuel compositions," WO 2009131510 (A1), 2009.

[7] I. Kubičková and D. Kubička, "Utilization of triglycerides and related feedstocks for production of clean hydrocarbon fuels and petrochemicals: a review," Waste and Biomass Valorization, vol. 1, no. 3, pp. 293-308, 2010.

[8] T. Morgan, D. Grubb, E. Santillan-Jimenez, and M. Crocker, "Conversion of triglycerides to hydrocarbons over supported metal catalysts," Topics in Catalysis, vol. 53, no. 11-12, pp. 820829, 2010.

[9] P. T. Do, M. Chiappero, L. L. Lobban, and D. E. Resasco, "Catalytic deoxygenation of methyl-octanoate and methylstearate on $\mathrm{Pt} / \mathrm{Al}_{2} \mathrm{O}_{3}$," Catalysis Letters, vol. 130, no. 1-2, pp. 9-18, 2009.

[10] J. Wildschut, F. H. Mahfud, R. H. Venderbosch, and H. J. Heeres, "Hydrotreatment of fast pyrolysis oil using heterogeneous noble-metal catalysts," Industrial and Engineering Chemistry Research, vol. 48, no. 23, pp. 10324-10334, 2009.

[11] J. G. Na, B. E. Yi, J. N. Kim et al., "Hydrocarbon production from decarboxylation of fatty acid without hydrogen," Catalysis Today, vol. 156, no. 1-2, pp. 44-48, 2010.

[12] S. Lestari, P. Mäki-Arvela, I. Simakova, J. Beltramini, G. Q. M. Lu, and D. Y. Murzin, "Catalytic deoxygenation of stearic acid 
and palmitic acid in semibatch mode," Catalysis Letters, vol. 130, no. 1-2, pp. 48-51, 2009.

[13] B. Donnis, R. G. Egeberg, P. Blom, and K. G. Knudsen, "Hydroprocessing of bio-oils and oxygenates to hydrocarbons. Understanding the reaction routes," Topics in Catalysis, vol. 52, no. 3, pp. 229-240, 2009.

[14] P. Šimáček, D. Kubička, G. Šebor, and M. Pospíšil, "Hydroprocessed rapeseed oil as a source of hydrocarbon-based biodiesel," Fuel, vol. 88, no. 3, pp. 456-460, 2009.

[15] D. Kubička and J. Horáček, "Deactivation of HDS catalysts in deoxygenation of vegetable oils," Applied Catalysis A, vol. 394, no. 1-2, pp. 9-17, 2011.

[16] S. Bezergianni, A. Kalogianni, and A. Dimitriadis, "Catalyst evaluation for waste cooking oil hydroprocessing," Fuel, vol. 93, pp. 638-641, 2012.

[17] S. Bezergianni, A. Dimitriadis, A. Kalogianni, and P. A. Pilavachi, "Hydrotreating of waste cooking oil for biodiesel production. Part I: effect of temperature on product yields and heteroatom removal," Bioresource Technology, vol. 101, no. 17, pp. 6651-6656, 2010.

[18] S. Bezergianni, A. Dimitriadis, T. Sfetsas, and A. Kalogianni, "Hydrotreating of waste cooking oil for biodiesel production. Part II: effect of temperature on hydrocarbon composition," Bioresource Technology, vol. 101, no. 19, pp. 7658-7660, 2010.

[19] J. Mikulec, J. Cvengroš, Ľ. Joríková, M. Banič, and A. Kleinová, "Second generation diesel fuel from renewable sources," Journal of Cleaner Production, vol. 18, no. 9, pp. 917-926, 2010.

[20] Ch. Templis, A. Vonortas, I. Sebos, and N. Papayannakos, "Vegetable oil effect on gasoil HDS in their catalytic co-hydroprocessing," Applied Catalysis B, vol. 104, no. 3-4, pp. 324-329, 2011.

[21] J. Walendziewski, M. Stolarski, R. Łużny, and B. Klimek, "Hydroprocesssing of light gas oil-rape oil mixtures," Fuel Processing Technology, vol. 90, no. 5, pp. 686-691, 2009.

[22] R. Tiwari, B. S. Rana, R. Kumar et al., "Hydrotreating and hydrocracking catalysts for processing of waste soya-oil and refinery-oil mixtures," Catalysis Communications, vol. 12, no. 6, pp. 559-562, 2011.

[23] S. Bezergianni, A. Kalogianni, and I. A. Vasalos, "Hydrocracking of vacuum gas oil-vegetable oil mixtures for biofuels production," Bioresource Technology, vol. 100, no. 12, pp. 30363042, 2009. 

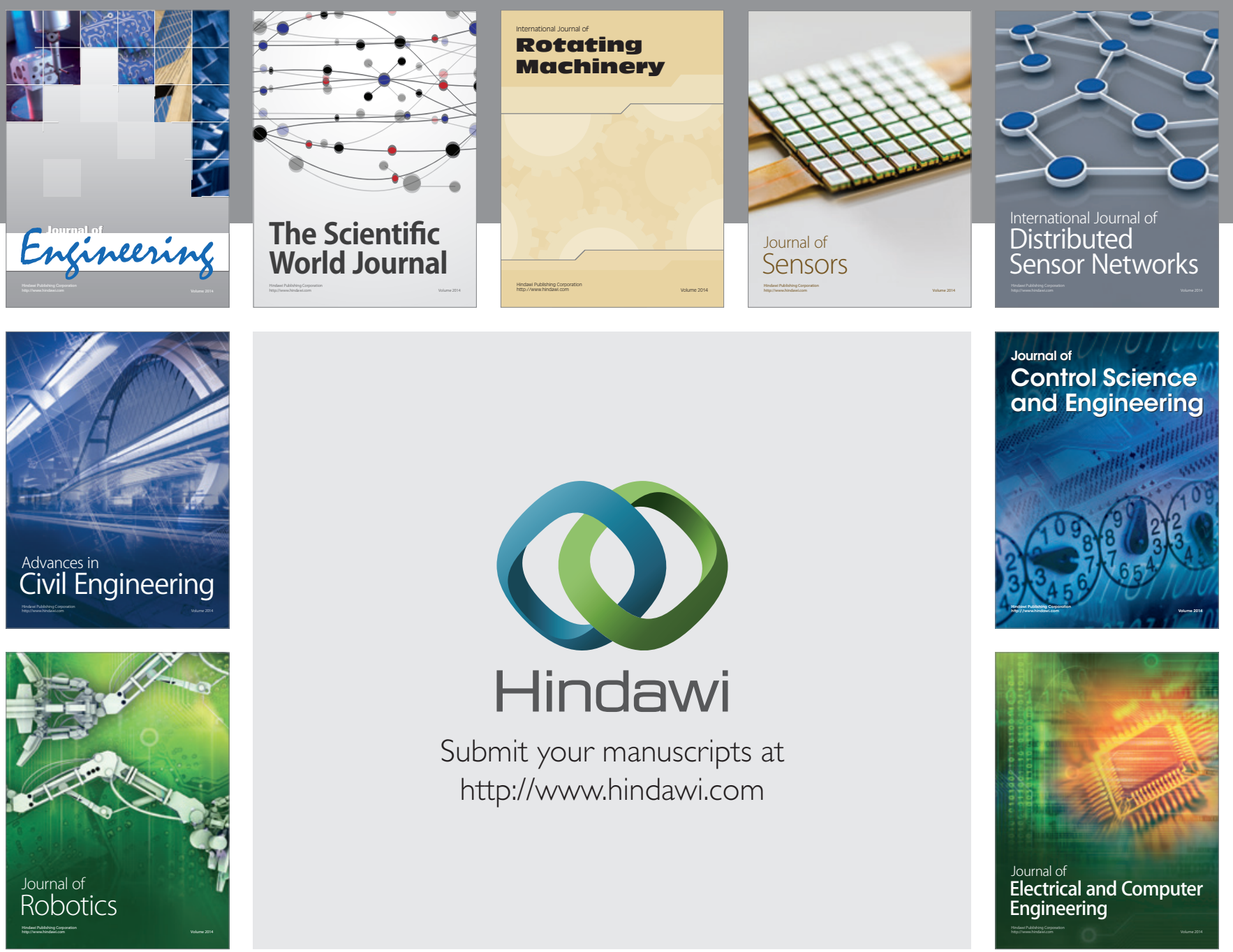

Submit your manuscripts at

http://www.hindawi.com
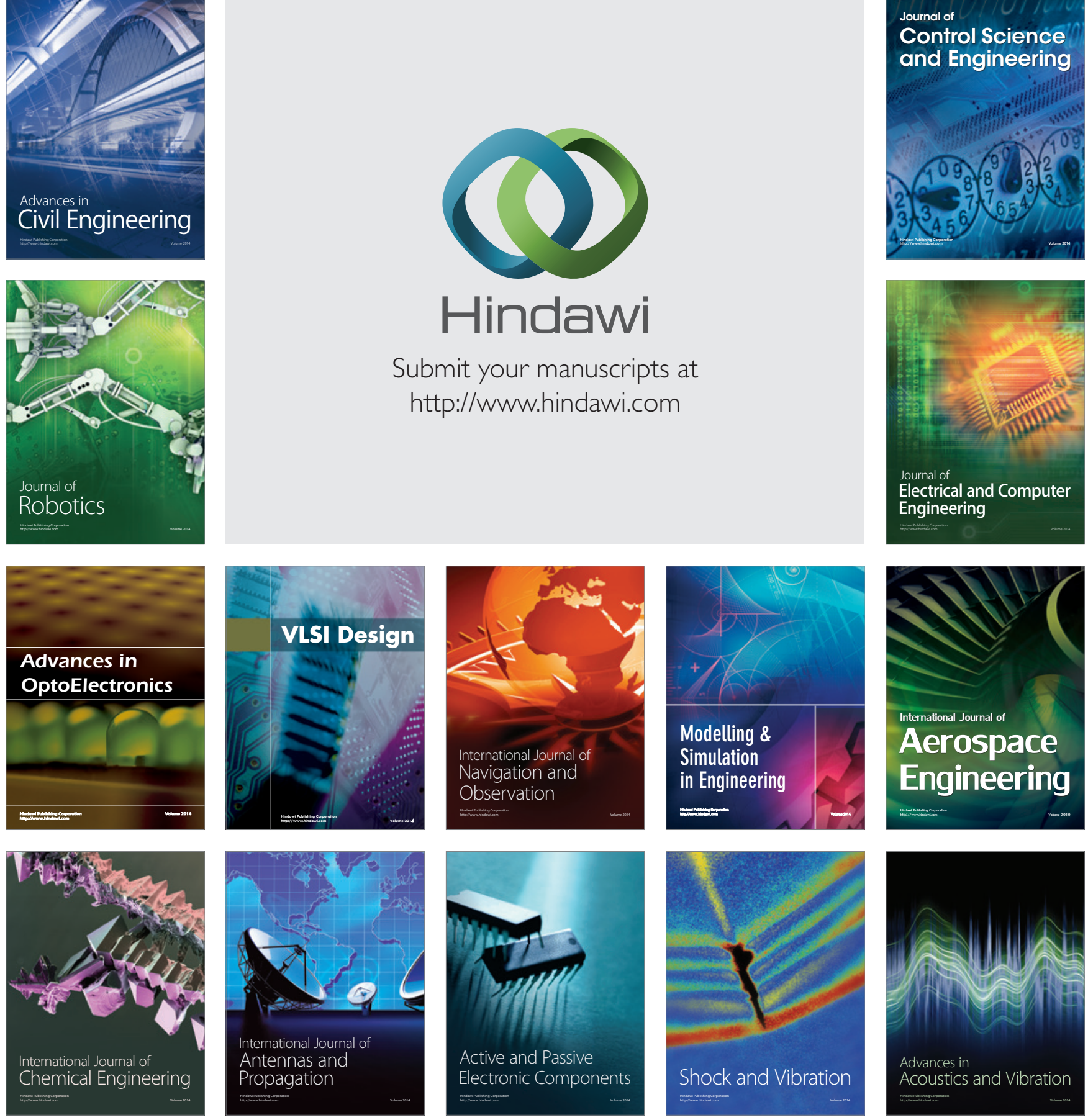